\title{
Research on Mathematics Teaching under Network Environment
}

\author{
Suping Qian \\ School of Accounting and Finance \\ Wuxi Institute of Commerce \\ Wuxi, China \\ qiansuping@wxic.edu.cn
}

\author{
Qiming Feng \\ Department of Mathematics \\ Wuxi Institute of Commerce \\ Wuxi, China \\ feng_qiming@163.com
}

\begin{abstract}
The research on mathematics teaching under network environment is one of the important parts in teaching research nowadays, which is of great significance for promoting deepening reform of mathematics teaching in higher vocational colleges. This paper introduces the advantages of mathematics teaching under network environment, the construction of mathematical resource base and the feasibility of its development in higher vocational colleges, and it also provides an example and set directions for other schools to construct their own teaching resource data center.
\end{abstract}

Keywords-Network environment; Mathematics teaching; Feasibility; Higher vocational colleges

\section{INTRODUCTION}

Higher vocational mathematics teaching is based on the concept of quality education. In accordance with the idea, we should deepen the teaching reform of the course, and make the mathematics course serve for quality education, innovation education and entrepreneurship education. Higher mathematics is an important tool for students who major in professional courses of higher vocational education, it should not only provide basic mathematical knowledge and mathematical methods for them to learn the subsequence courses and solve practical problems, but also provide the necessary conditions for the ability to train the students' thinking and to analyze and solve the problem. Modern education technology symbolized by network is the basic environment and real need for the subject of mathematics to develop the teaching reforms. The teaching environment which is based on the network can break through the limit of traditional teaching of mathematics and promote teaching reforms' thinking and the practice of new teaching theory in higher vocational colleges. The mathematics teaching which is based on the network should adjust and adapt such a kind of thinking, optimize and prove the teaching strategy, explore and choose appropriate teaching model. Therefore, in order to enhance the effectiveness of mathematics education, it is of great significance to explore the further reformation of mathematics teaching in higher vocational education.

\section{The STAtUS OF MATHEMATics Teaching}

It is a common phenomenon to ignore the importance of mathematics course. Some students think one-sided vocational education is practical technology teaching, and mathematics is not very useful for professional courses and future work, which leads to their lack of learning motivation [1].

At the same time, in the higher vocational colleges, the students' mathematics foundation is weak, and they do not have good learning habits and correct learning methods when they are learning mathematics, all these make them have a strong resistance to mathematics learning. At present, the students are shown diversity. Generally, there are two main types: one is a high school graduates who take part in the general college entrance examination, among which there are science students and literary students. The other is the secondary vocational school graduates [2]. The characteristics of higher vocational education determines there may be both literary and science students in the same class. And this brings a great difference between the mathematics foundation and acceptance ability of the same class students, which will bring great difficulties to teachers' teaching. It is also very difficult to achieve the overall development of the same class students [3].

On the other hand, due to the late start of higher vocational education in China, the depth of educators' research on higher vocational education is far from enough, regardless of teaching contents or teaching methods, there is still much room for improvement and improvement. There are the main reasons for the loss of students' interest in learning. Firstly, most of the higher vocational mathematics textbooks pay too much attention to theory itself, but ignore the application. Secondly, teachers in the teaching process echo what the books say, overemphasize the proof of theorem and definition, but ignore the cultivation of students' ability to use.

Furthermore, higher vocational education is closely related to social economy, it is necessary to adopt the most flexible and convenient means and methods to cultivate more practical talents for the society. Therefore, in order to meet the training needs of professional technology, such as the professional courses, the experiment of specialized courses and some skills courses that are urgently needed by society should be increased, but the class hours of basic courses such as mathematics will be reduced. Obviously, mathematics teaching 
is facing many difficulties, such as too much content, few classes and fast progress, which have brought huge obstacles to students' learning.

\section{THE ADVANTAGES OF NETWORK TEACHING}

The network education environment is to use modern teaching theory to give all kinds of educational functions and resources of the network, and provide a teaching and learning environment for educators and learners. In the network environment, distance is no longer a barrier for people to communicate, and students can accomplish difficult and complex tasks in collaboration. At the same time, with the help of teaching resources, network multimedia technology can let the learning content extend in time and space, students through collecting and processing information, judgment, making decision, try to make reasonable inferences or bold guesses, so that their comprehensive quality can be further improved [4]. With the help of network multimedia technology, teachers can not only play a leading role, but also respect the subjectivity of students, provide students with abundant learning resources and expand their learning space, so as to achieve harmony and unity between teaching and learning.

Teaching in the traditional classroom environment often meets the situation of teacher role from assistance to master. Teachers who are used to control the whole teaching process intentionally or unintentionally take the action of from participation, guide and consult to lead, control and lecturing in the course of students' learning. Students' learning becomes a logical and orderly arrangement of teachers. However, in the network environment, the establishment of learning activities is realized by collaborative platform built by computer related technology. Teachers and students can't get away from this platform to achieve learning objectives, thus ensuring the stability of learning and the rational allocation of control rights [5]. At the same time, the network environment can create a relaxed psychological environment for students' learning, and can more effectively carry out autonomous learning and collaborative learning of mathematics.

\section{THE CONSTRUCTION OF RESOURCE BASE}

\section{A. the meaning of construction}

Under the network environment, mathematics teaching is a new teaching method that combines network information resources, human resources and mathematics contents together to complete the teaching task in the teaching process. Therefore, building a practical and efficient mathematical material database and teaching model library is the key to realize the integration of the network multimedia technology and the mathematics subject. The database of mathematical materials is a collection of teaching materials and expressions. It can provide a large amount of knowledge and information for teachers and students to use freely in classroom teaching [5]. A school, a region, the whole country, and the world's teaching information resources which are retrieved and reorganized by teachers and students in classroom teaching can be flexibly integrated into the current mathematics teaching practice. The teaching model library is the combination of the teaching mode used in the teaching. In the course of teaching, teachers combine different material, different data presentation and teaching mode to cope with various teaching conditions.

At the same time, the teaching experience and methods of excellent teachers, advanced learning theories and teaching models at home and abroad should be introduced into the library to provide reference for teachers [6]. At present, higher vocational colleges have modern educational facilities such as high-speed broadband campus network, mobile network, multimedia reading room etc., these hardware facilities meet the requirements of mathematics teaching under the network environment. The establishment of a mathematical resource base is based on the collection and collation of network teaching data and the analysis of the usage patterns.

\section{B. Condition analysis}

Higher vocational colleges have modern educational facilities, and have the hardware requirements for mathematics teaching in the network environment, but there are also some shortcomings, which are as follows.

- The network information server group has been set up, which can provide services such as Web browsing, email, video on demand, file transfer, database and so on. However, the electronic bulletin board (BBS) and other services are less and cannot be completely open to the whole institute.

- The website of the institute, and the various departments are in the construction. A number of application systems, such as educational administration system, student management system, equipment management system, office system, network teaching platform, excellent course platform, and digital teaching resource platform have been initially implemented. These have carried out a preliminary support to the teaching and management of the institute. However, some application systems are not fully used, and its application effect is not yet obvious, Information island makes information cannot be shared, and the lack of digital teaching resources still exists.

- The integrated management of information and the construction of service system are in the initial stage. The school information leadership team and expert advisory group, responsible for the school leaders, have been established. At the same time, the network center, which is responsible for the operation and maintenance of the campus network, has been set up. However, there are few people in the network center and the task is heavy. Teachers and managers are not fully used to the use of information technology for daily teaching and work. Information education and promotion are in its infancy.

- The system security and identity authentication system have been established. However, the infrastructure of digital campus is relatively backward, application systems are not interconnected, system security and identity authentication are relatively backward, there is no uniform technical standard (data standard, interface 
standard, application standard), and no data exchange center.

- The hardware environment of the campus network is in the phase of planning again and expansion. Various campus servers and other facilities are rich, providing a variety of independent application platform systems. Network link planning and design are carried out among several campuses, and interconnected engineering is implemented. The project of planning again and reconstructing the old equipment and network has been gradually carried out. However the old server and other equipment are obsolete and the rate of failure is increased, and the security planning is imperfect, which affects the safe operation of the service.

\section{Design principles}

In order to meet the needs of the system to the maximum, it is necessary to develop practical management system and facilitate further expansion of the system. Therefore, the following principles are observed in the design of the system [7].

- Standardization principle: the classification code of data strictly adhered to the existing national standards and industry standards.

- Completeness principle: the completeness of the data should ensure that the information stored in the database should be sufficient to meet the daily operation needs of the system. And the completeness of the function should be designed according to the requirements and provide a friendly user interface.

- Extensibility principle: system functions and databases must be extensible.

- The principle of technology advancement: the design of the system function target should have a high starting point. It should give priority to the advanced nature of the system while comparing the performance and price.

\section{System implementation}

The network teaching resource center includes the construction of resource base and the network teaching system. The teaching system includes functional modules such as teaching home page, course information, teaching content management, teaching communication, teaching evaluation, teaching organization and management, tracking and statistical analysis, forums and questionnaires, system management functions and so on.

The implementation of the system needs to complete some of the following tasks, such as system organization framework, interface design and implementation, login module function realization, resource library function realization (edit, view, picture display, video conversion and display, etc.), the realization of system logic and the realization of system interface. Function testing, performance testing, usability testing and safety testing methods are implemented, such as system interface implementation, resource repository submission, resource repository query management module and other key functional modules.

By studying the function, technology, architecture of the network teaching resource library, combining with database management technology, using advanced computer software technology, a network teaching data center which supporting teaching activities would be established, and its importance is to solve the problem of the decentralization of teaching resource management [8].

\section{CONCLUSION}

There are three advantages for the mathematics teaching under the network environment in higher vocational colleges. Firstly, the development of students' thinking and good teachers' team in higher vocational colleges provide the basis for the development of mathematics teaching under the network environment. Because the logical thinking and abstract thinking of the higher vocational students are gradually mature, and the abstract thinking occupies the dominant position, so the students will have a strong ability to learn mathematics. Secondly, the teachers in vocational colleges actively participate in mathematics teaching reform, so that all students can participate in the learning process of mathematics, solve mathematical problems one by one, experience the feeling of success, which lay a solid foundation for the development of mathematics teaching under the network environment. Thirdly, the teaching reform of higher vocational colleges, such as the flexibility of teaching program, the differentiation of teaching contents, looking down on the theory and strengthening the application, looking down on the result and emphasis on the process, provides a good atmosphere for the development of mathematics teaching under the network environment.

The widespread use of mathematical resource base can improve teachers' working efficiency, improve students' autonomous learning ability, establish mutual communication and feedback between teachers and students, or students and students, and achieve the goal of improving the learning efficiency.

The teaching of Mathematics under the network environment is to integrate the network technology with the mathematics course, and its core is teaching rather than technical attempt. The learning under the network environment has more advantages than other methods, the study of mathematics teaching under the network environment is being accepted and put into practice by many educators, but how to give full play to more value is a problem that every teacher needs to think and practice repeatedly.

The method of establishing network teaching resources in this paper can be used in the teaching of other courses. 


\section{ACKNOWLEDGMENT}

The research work was supported by Jiangsu Province fourth 333 high-level personnel training project.

\section{REFERENCES}

[1] Fu Yanru,Ma De.The project oriented teaching design of mathematics curriculum software under the network environment.Distance education in China, vol. 2, pp. 57-72, January 2016.

[2] Wang Lina,ChenLing.An empirical study on the effect of operation situation on children's mathematical problems in the classroom network environment. E-education research, vol. 9, pp. 58-63, September 2014.

[3] Zhang Honghong. Preliminary study on the reform of mathematics teaching in higher vocational colleges. Journal of Shanxi Normal University (SOCIAL SCIENCE EDITION), vol.36,pp. 63-69, November 2009.

[4] Feng Xingbao.Research on multi-dimensional classroom teaching model based on mobile Internet Environment.Chian adult education, vol.7, pp. 106-108, July 2017.

[5] Qin Anlan. A comparative study of network based cooperative learning and traditional cooperative learning.Electrochemistry education research, vol.30,pp. 46-51, June 2004.

[6] Jiang Jiping.An empirical study on the relationship between learner autonomy and academic achievement of distance learners in the network environment. Adult education,vol. 2, pp. 29-34, Februaryr 2018.

[7] Zhang Bo, Qian Lin. Several special relationships in the integration of computer and mathematics teaching. Journal of mathematics education, vol.1,pp. 71-75, November 2002.

[8] Yuan Xiuping.The implementation mode of mixed teaching under the network environment. Education modernization,vol.35,pp.35-36, November 2016. 